\title{
CORRESPONDENCE
}

\section{Perinatal transmission of acute dengue: First case reported in Turks and Caicos Islands}

\author{
Lorena Soler Casale*, Estela Quintana Livingston, Christa Teves
}

Department of Paediatrics, Turks and Caicos Islands Hospital, Providenciales, Turks and Caicos Islands, British West Indies

\begin{abstract}
We report a newborn baby boy readmitted to the hospital at 7 days of life with acute dengue due to vertical transmission. A 32-year-old primigravida at 38+ weeks of gestation, with no antenatal care and with severe pre-eclampsia, delivered a normal term baby boy by spontaneous vaginal delivery and recovered uneventfully during her postpartum period. The normal term baby boy was admitted to the Neonatal Intensive Care Unit (NICU) for five days due to low birth weight for gestational age, and was asymptomatic except for the transient initial mild thrombocytopenia, from which he recovered uneventfully during the following 48 $\mathrm{h}$. He developed a high-grade fever on day 7 of post-natal life ( $48 \mathrm{~h}$ after being discharged). The baby was treated with appropriate fluid management of antibiotics and paracetamol administered intravenously. Blood cultures were negative and other laboratory findings were unremarkable. He did not have a fever during his admission and was discharged uneventfully after seven days. Clinical diagnosis of acute dengue virus infection was confirmed by laboratory tests of $\operatorname{IgG}$ and $\operatorname{IgM}$ antibodies in both the baby (on the readmission day) and mother (from the first blood sample on the day of delivery, seven days prior to readmission). The mother acknowledged having fever and bone pain four days prior to delivery; however, the information was not relayed when she was admitted during labor due to language barriers.
\end{abstract}

Keywords: Neonatal dengue; vertical transmission; perinatal dengue; maternal dengue

ARTICLE INFO

Received: January 18, 2016

Accepted: January 25, 2016

Available online: July 4, 2016

*CORRESPONDING AUTHOR

Dr. Lorena Soler Casale, Department of Paediatrics, Turks and Caicos Islands Hospital, InterHealth Canada (TCI) Ltd., Providenciales, Turks and Caicos Islands, TKCA 1ZZ, British West Indies; LSoler@interhealthcanada.tc

\section{CITATION}

Casale LS, Livingston EQ, Teves C. Perinatal transmission of acute dengue: First case reported in Turks and Caicos Islands. J Pediatr Dis 2017; 1: 103. doi: 10.24294/jpedd.v1i0.103

COPYRIGHT

Copyright (C) 2017 by author(s) and EnPress Publisher LLC. This work is licensed under the Creative Commons Attribution-NonCommercial 4.0 International License (CC BY-NC 4.0). http://creativecommons.org/licenses/ by/4.0/

\section{Introduction}

A 32-year-old primigravida at about 38 weeks gestation according to the patient, with no previous antenatal care and with a history of lower abdominal pain for $12 \mathrm{~h}$, was admitted to the Turks and Caicos Islands Hospital. Language barriers presented communication difficulties in spite of the availability of translation services. During examination, the mother was in obvious distress; mucus membranes were pink and moist, and bilateral pedal edema was noted. Her fundal height was 34 weeks. At admission, she was afebrile (axillary temperature of $36.2^{\circ} \mathrm{C}$ ), pulse was $84 / \mathrm{min}$, respiratory rate was $20 / \mathrm{min}$, and $\mathrm{BP}$ was $185 / 101 \mathrm{mmHg}$. Urine tested positive for protein (specimen taken via catheter). She was diagnosed with severe preeclampsia and treated on admission. The cervix was fully dilated with bulging membranes, which ruptured spontaneously 20 min after admission. Cardiotocography (CTG) showed a reactive fetal heart rate with a baseline of $138 \mathrm{bpm}$. The complete blood count $(\mathrm{CBC})$ revealed hemoglobin $(7.8 \mathrm{~g} /$ $\mathrm{dL})$, hematocrit $(25.8 \%)$, platelet count $\left(263 \times 10^{9} / \mathrm{L}\right)$, WBC $\left(13.44 \times 10^{9} / \mathrm{L}\right)$ and absolute neutrophils $\left(9.59 \times 10^{9} / \mathrm{L} ; 71.4 \%\right)$. Coagulation, liver and renal function profiles revealed normal results.

A live term male infant was delivered with the aid of an episiotomy. His birth weight was $2060 \mathrm{~g}$ with Apgar scores of 9 and 10 at 1 and $5 \mathrm{~min}$, respectively. Vitamin $\mathrm{K}(1 \mathrm{mg})$ was given intramuscularly via injection as per routine protocol. No abnormalities were detected during neonatal examination. The postpartum period was uneventful. The mother was discharged on the second day and was prescribed antihypertensives. No fever, pain or abnormal 
bleeding was noted during the two-day inpatient stay.

The baby was admitted to the Neonatal Intensive Care Unit (NICU) due to low birth weight for gestational age. Enteral feeds were restricted for $24 \mathrm{~h}$. Appropriate IV fluids were administered. His initial CBC showed hemoglobin $(18.1 \mathrm{~g} / \mathrm{dL})$, hematocrit $(53.7 \%)$, WBC $\left(10.19 \times 10^{9} / \mathrm{L}\right)$ and platelet count $\left(125 \times 10^{9} / \mathrm{L}\right.$, which increased to $138 \times 10^{9} / \mathrm{L}$ after $48 \mathrm{~h}$ ). Bilirubin was maintained below phototherapy level with a maximum of $254 \mathrm{mmol} / \mathrm{L}$. Maternal Group B Streptococcal (GBS) status was unknown but the baby was asymptomatic at term; therefore, antibiotics were not prescribed. Blood cultures were negative after $48 \mathrm{~h}$. No fever or distress was noted during admission. Enteral feeds were started and increased as tolerated until the baby was fully fed by mouth. The baby was discharged at five-days old, bottle-fed and breastfed ad lib on demand, with a weight of $2000 \mathrm{~g}$ and normal physical exam results.

After $48 \mathrm{~h}$ of being discharged, at 7 days of life, the baby was brought to the Emergency Department with pyrexia (axillary temperature of $39.7^{\circ} \mathrm{C}$ ). Examination results were normal except for persistent grunting respiration without oxygen requirements. Normal $\mathrm{CBC}$ with platelet count increased to $145 \times 10^{9} / \mathrm{L}$. Blood and urine cultures were negative. Other laboratory findings were unremarkable. Ascites and pleural effusion were excluded by abdominal ultrasound and chest X-ray. There were no rashes, bleeding or petechiae. The diagnosis for dengue was confirmed with $\operatorname{IgM}$ and IgG antibodies specific to dengue virus. Maternal serology for dengue was requested from the maternal blood sample sent seven days previously during admission for labor. The IgM and IgG were denguepositive. The mother acknowledged having fever and bone pain four days prior to delivery, information which was not provided during admission one week earlier.

During hospitalization, the baby was treated with appropriate fluid management of antibiotics and paracetamol via IV. There was no recurrent pyrexia during his stay and he was discharged uneventfully after seven days. He was followed-up at our outpatient department with normal growth and development at three months of age.

\section{Discussion}

\section{Tropical islands in the Caribbean}

An infrequent number of cases of vertical transmission of acute dengue in neonates were reported in literature ${ }^{[1,2]}$. Some reviews included confirmed transmissions but in asymptomatic newborns ${ }^{[3]}$. The rate of vertical transmission varies from $1.6 \%$ to $10.5 \%$ as reported in some publications, with a seroconversion of the fetus on average at day 6 of in utero infection ${ }^{[4-7]}$. Low birth weight, preterm delivery, abortion, premature rupture of membranes, pre-eclampsia, maternal or fetal death, and maternal or neonatal thrombocytopenia were fetal-maternal compli-cations reported with dengue infections during pregnancy, especially hemorrhagic dengue $\mathrm{e}^{[8-14]}$.

When working in endemic areas, higher levels of awareness and early diagnosis are crucial to reduce morbidities and mortalities associated with dengue fever ${ }^{[3,15-19]}$. Clinical management of dengue in newborns may vary depending on the severity of illness. Symptomatic and supportive care remain the mainstay of treatment ${ }^{[20-23]}$.

This is the first case of perinatal trans-mission of dengue in a term baby reported in Turks and Caicos Islands (Caribbean). Retro-spectively, the limited history provided due to the language barrier, lack of antenatal care, combined with the severity of the maternal medical condition at admission, contributed to the delayed diagnosis of neonatal dengue in this case.

\section{Conclusion}

Maternal dengue serology should be considered near delivery if signs of perinatal infection are suspected, even if the newborn is asymptomatic. It is recommended that evidence-based clinical guidelines are developed to facilitate identification of those mothers and babies at risk in areas where dengue fever is endemic.

\section{Conflict of interest}

The authors declared no potential conflict of interest with respect to the research, authorship, and/ or publication of this article.

\section{Acknowledgements}

The authors thank Joanne Kinborough Mata for refining the language this manuscript. We thank Dr. Nadia Astwood, Director of Health Services and Chief Medical Officer, Ministry of Health of Turks and Caicos Islands and Dr. Denise Braithwaite, Chief of Medical Services at Turks and Caicos Islands Hospital, InterHealth Canada (TCI) Ltd., for their kind permission to publish these findings. 


\section{References}

1. Boussemart T, Babe P, Sibille G, Neyret C, Berchel C. Prenatal transmission of dengue: Two new cases. J Perinatol 2001; 21(4): 255 - 257. doi: 10.1 038/sj.jp.7200530.

2. Chin PS, Khoo A, Asmah Hani AW, Chem YK, Norizah I, et al. Acute dengue in a neonate secondary to perinatal transmission. Med J Malaysia 2008; 63(3): 265 - 266.

3. Salgado DM, Rodríguez JA, Lozano L del P, Zabaleta TE. Dengue perinatal (Spanish) [Perinatal dengue]. Biomédica 2013; 33(Suppl 1): 14 - 21. doi: 10.7705/biomedica.v33i0.1449.

4. Pouliot SH, Xiong X, Harville E, Paz-Soldan V, Tomashek KM. Maternal dengue and pregnancy outcomes: A systematic review. Obstet Gynecol Surv 2010; 65(2): 107 - 118. doi: 10.1097/OGX.0b 013e3181cb8fbc.

5. Berberian G, Fariña D, Rosanova MT, Hidalgo $\mathrm{S}$, Enría D, et al. Dengue perinatal (Spanish) [Perinatal dengue infection]. Arch Argent Pediatr 2011; 109(3): 232 - 236.

6. Kariyawasam S, Sennanayake H. Dengue infections during pregnancy: Case series from a tertiary care hospital in Sri Lanka. J Infect Dev Ctries 2010; 4(11): 767 - 775. doi: 10.3855/jidc.90 8.

7. Chan M, Johansson MA. The incubation periods of dengue viruses. PLoS ONE 2012; 7(11): e50972. doi: 10.1371/journal.pone.0050972.

8. Basurko C, Carles G, Youssef M, Guindi WEL. Maternal and foetal consequences of dengue fever during pregnancy. Eur J Obstet Gynecol Reprod Biol 2009; 147(1): 29 - 32. doi: 10.1016/j.ejogrb.2 009.06.028.

9. Ribeiro CF, Lopes VGS, Brasil P, Coelho J, Muniz $\mathrm{AG}$, et al. Perinatal transmission of dengue: A report of 7 cases. J Pediatr 2013; 163(5): 1514 1516. doi: 10.1016/j.jpeds.2013.06.040.

10. Thaithumyanon P, Thisyakorn U, Deerojnawong $\mathrm{J}$, Innis BL. Dengue infection complicated by severe hemorrhage and vertical transmission in a parturient woman. Clin Infect Dis 1994; 18(2): 248 - 249. doi: 10.1093/clinids/18.2.248.

11. Chye JK, Lim CT, Ng KB, Lim JMH, George R, et al. Vertical transmission of dengue. Clin Infect Dis 1997; 25(6): 1374 - 1377. doi: 10.1086/516126.

12. Carles G, Talarmin A, Peneau C, Bertsch M. Dengue et grossesse. Étude de 38 cas en Guyane française. (French) [Dengue fever and pregnancy. A study of 38 cases in French Guiana]. J Gynecol Obstet Biol Reprod (Paris) 2000; 29(8): 758 - 762.

13. Castellanos MJ, Hernández PP, Arellano CB, Newton SOA, Espinoza GF. Reporte de un caso de dengue neontatal (Spanish) [Neonatal dengue. Case report]. Bol Med Hosp Infant Mex 2006; 63(3): $202-206$.

14. Jain A, Chaturvedi UC. Dengue in infants: An overview. FEMS Immunol Med Microbiol 2010; 59: 119 - 130. doi: 10.1111/j.1574-695X.2010.006 70.x.

15. Kaur G, Soni S, Aggarwal S, Saini AS. Vertical transmission of dengue - A case report. J Obstet Gynecol India 2014; 64(Suppl 1): 1 - 2. doi: 10.10 07/s13224-012-0253-6.

16. Sinhabahu VP, Sathanathan R, Malavige GN. Perinatal transmission of dengue: A case report. BMC Res Notes 2014; 7: 795. doi: 10.1186/17560500-7-795.

17. Adam I, Jumaa AM, Elbashir HM, Karsany MS. Maternal and perinatal outcomes of dengue in PortSudan, Eastern Sudan. Virol J 2010; 7: 153. doi: 10.1186/1743-422X-7-153.

18. Petdachai W, Sila' on J, Nimmannitya S, Nisalak A. Neonatal dengue infection: Report of dengue fever in a 1 day-old infant. Southeast Asian J Trop Med Public Health. 2004; 35(2): 403 - 407.

19. Janjindamai W, Pruekpraset P. Perinatal dengue infection: A case report and review of literature. Southeast Asian J Trop Med Public Health 2003; 34(4): $793-796$.

20. World Health Organization and the Special Programme for Research and Training in Tropical Diseases (TDR). Dengue: Guidelines for diagnosis, treatment, prevention and control: New edition. Geneva: World Health Organization; 2009. p. 147.

21. World Health Organization. Global strategy for dengue prevention and control, 2012 - 2020: WHO report. Geneva: World Health Organization; 2012. p. 43.

22. World Health Organization and Special Programme for Research and Training in Tropical Diseases. Handbook for clinical management of dengue: WHO and Special Programme for Research and Training in Tropical Diseases (TDR) report. Geneva: World Health Organization; 2012. p. 111.

23. National Vector Borne Disease Control Programme. National guidelines for clinical management of dengue fever. New Delhi: World Health Organization; 2015. p. 37. 